\title{
WEYL'S THEOREM FOR CLASS A OPERATORS
}

\author{
ATSUSHI UCHIYAMA*
}

Abstract. In this paper, we show that Weyl's theorem holds for class $A$ operators under a certain condition. We also show that a class $A$ operator whose Weyl spectrum equals to the one-point set $\{0\}$ is always compact and normal. theorem.

Mathematics subject classification (2000): 47A53, 47B20.

Key words and phrases: Class $A$ operators, $w$-hyponormal operators, continuity of spectra, Weyl's

\section{REFERENCES}

[1] A. AluthGE AND D. WANG, An operator inequality which implies paranormality, Math. Inequal. Appl. 2 (1999), 307-315.

[2] S. K. BERBERIAN, An extension of Weyl's theorem to a class of not necessarily normal operators, Michigan Math. J. 16 (1969), 273-279.

[3] L. A. CoBuRn, Weyl's theorem for non-normal operators, Michigan Math. J. 13 (1966), 285-288.

[4] М. Сно-, M. ITOH AND S. ŌSHIRO, Weyl's theorem holds for p-hyponormal operators, Glasgow Math. J. 39 (1997), 217-220.

[5] T. FURUTA AND M. ITO AND T. YAMAZAKI, A subclass of paranormal operators including class of log-hyponormal and several related classes, Scientiae Mathematicae 1 (1998), 389-403.

[6] F. HANSEN, An inequality, Math. Ann. 246 (1980), 249-250.

[7] J. G. STAMPFLI, Hyponormal operators, Pacific J. Math. 12 (1962), 1453-1458.

[8] A. UCHIYAMA,, Berger-Shaw's theorem for p-hyponormal operators, Integral Equations and Operator Theory 33 (1999), 221-230.

[9] A. UCHIYAMA,, Inequalities of Putnam and Berger-Shaw for p-quasihyponormal operators, Integral Equations and Operator Theory 34 (1999), 91-106.

[10] D. XIA, On the non-normal operators - semihyponormal operators, Sci. Sinica. 23 (1980), 700-713. 